\title{
Management of the asymptomatic BRCA mutation carrier
}

This article was published in the following Dove Press journal:

The Application of Clinical Genetics

23 November 2010

Number of times this article has been viewed

\author{
Paige Teller' \\ Rita K Kramer ${ }^{2}$ \\ 'Surgical Oncology, ${ }^{2}$ Medical \\ Oncology, Medical University of South \\ Carolina, Charleston, SC, USA
}

Correspondence: Paige Teller Medical University of South Carolina,

25 Courtenay Drive, ART 7018,

Charleston, SC 29425, USA

$\mathrm{Tel}+\mathrm{I} 843876018 \mathrm{I}$

Fax +I 8438764705

Email teller@musc.edu
Abstract: Current management of an asymptomatic $B R C A$ mutation carrier includes early initiation and intensive cancer screening in combination with risk reduction strategies. The primary objectives of these interventions are earlier detection and cancer prevention to increase quality of life and prolonged survival. Existing recommendations are often based on the consensus of experts as there are few, supportive, randomized control trials. Management strategies for unaffected patients with $B R C A$ mutations are continually redefined and customized as more evidence-based knowledge is acquired with regard to current intervention efficacy, mutation-related histology, and new treatment modalities. This review provides an outline of current, supported management principles, and interventions in the care of the asymptomatic $B R C A$ mutation carrier. Topics covered include surveillance modalities and risk reduction achieved through behavioral modification, chemoprevention, and prophylactic surgery.

Keywords: high risk, screening, risk reduction, hereditary breast cancer syndrome

\section{Introduction \\ $B R C A$ prevalence and related cancer risk}

Breast cancer susceptibility genes, $B R C A 1$ and $B R C A 2$, were discovered in the early 1990s. ${ }^{1-3}$ Inheritance of a mutation in these tumor suppressor genes accounts for approximately $7 \%$ of breast and $10 \%$ of ovarian cancer cases. ${ }^{4}$ The estimated $B R C A 1$ and $B R C A 2$ mutation carrier frequencies in the general population are 1 in 300 and 1 in 800 , respectively. ${ }^{5}$ In the Ashkenazi Jewish population, the $B R C A$ mutation carrier frequency is as high as $1 \mathrm{in} 40 .^{6-9}$ These frequencies estimate that between 400,000 and 1 million individuals in the United States are gene mutation carriers. ${ }^{10}$ Despite the availability of $B R C A$ gene mutation testing for over a decade and increasing knowledge about related cancer risks, only $5 \%$ of the carrier population has been identified. ${ }^{11}$

\section{Risk of breast cancer}

The cumulative probability that a carrier of a mutation in $B R C A 1$ or $B R C A 2$ will develop breast cancer (penetrance) is uncertain and varies according to the population studied. The most comprehensive analysis of population-based studies reported a risk at age 70 of $65 \%$ for female $B R C A 1$ carriers and $45 \%$ for female $B R C A 2$ carriers. ${ }^{12}$ Risk for an individual female carrier is also influenced by family history. Women with relatives diagnosed with breast cancer at younger ages or bilateral breast cancer appear to be at higher risk. ${ }^{13}$ Location of the mutation on the gene may also impact cancer risk. Mutations located within the central region of the BRCA2 gene are associated with 
a higher risk of ovarian cancer and a lower risk of breast cancer. This region of the $B R C A 2$ has been designated the ovarian cluster region. ${ }^{13}$

The risk of contralateral breast cancer in a female $B R C A$ mutation carrier with a prior history of breast cancer is also increased. In a nested, case-control study of women diagnosed with unilateral breast cancer before age 55, women with contralateral breast cancer diagnosed 1 year or greater from the primary breast cancer were identified. ${ }^{14}$ These cases were then tested for mutations in BRCA1 and BRCA2. Carrying a $B R C A 1$ mutation was associated with a 4.5 -fold increased risk of developing contralateral cancer. ${ }^{14}$ The risk for $B R C A 2$ mutation carriers was increased by 3.4 -fold. ${ }^{14}$ The relative risk for $B R C A 1$ mutation carriers is inversely related to the age of first cancer diagnosis, with increased risk seen in those diagnosed with their first cancer at a younger age. ${ }^{14,15}$ The impact of age at first breast cancer diagnosis for contralateral cancer risk in $B R C A 2$ carriers is less clear. While one study showed a lower risk for patients who were older at the time of diagnosis with their first cancer, this difference was not statistically significant. ${ }^{15}$

The risk of breast cancer for men who carry a mutation in $B R C A 2$ is greater than that of the general population. The estimated cumulative risk by age 70 is $6.8 \% .{ }^{16}$ The risk for male carriers of BRCA1 mutations is less well established but also appears to be increased at $1.2 \%{ }^{16}$

\section{Risk of ovarian cancer}

The cumulative risk of ovarian cancer in $B R C A 1$ mutation carriers is estimated to be between $27 \%$ and $45 \%{ }^{11,17}$ There is also a significantly increased risk for fallopian tube cancer. ${ }^{17}$ Lifetime risk for the development of ovarian cancer in a BRCA2 mutation carrier ranges between $10 \%$ and $20 \%$. $^{12,18}$

\section{Risk of other cancers}

In addition to the increased risk of breast and ovarian cancer, carriers of mutations in $B R C A 1$ are reported to have a 2-fold to 3 -fold increased risk of pancreatic cancer. ${ }^{17,19}$ Prostate cancer risk does not appear to be increased, although the disease may occur at an earlier age. ${ }^{20}$ Additionally, BRCA1 mutation carriers have an increased lifetime risk of developing cancer in general than nonmutation carriers. A kin-cohort study revealed that by age 80 , a female mutation carrier's estimated risk of cancer was $98 \%$ as compared with a noncarrier whose risk was $32 \%$. ${ }^{18}$ This risk was estimated to be $59 \%$ for a male $B R C A 1$ mutation carrier as compared with $40 \%$ for a noncarrier. ${ }^{18}$

Carriers of $B R C A 2$ germ line mutations are also at increased lifetime risk of developing pancreatic cancer. ${ }^{21}$ Male $B R C A 2$ mutation carriers are at an increased risk of prostate cancer. ${ }^{21}$ These individuals have a 7-fold greater likelihood of being diagnosed with prostate cancer before the age of 65years than noncarriers. ${ }^{21}$ As with $B R C A 1$, the lifetime risk of any cancer in $B R C A 2$ mutation carriers is increased as compared with noncarriers with a $73 \%$ risk for women and $58 \%$ for men. ${ }^{18}$

\section{Surveillance}

Current screening recommendations for the asymptomatic $B R C A$ mutation carrier encompass examination, imaging, and laboratory evaluation. Surveillance for female carriers emphasizes screening techniques for breast and ovarian cancers. Recommendations for male carriers include breast and prostate cancer screening modalities. Screening does not reduce the risk of developing these cancers but may result in earlier detection. Early detection leads to earlier initiation of treatment when cancers may be more responsive and treatment may be more efficacious. The lack of scientific evidence to support some of these modalities requires providers to make informed decisions with their patients regarding the benefits, risks, and limitations of these screening options.

\section{Breast cancer screening}

Several national guidelines exist for breast cancer screening in women of average population risk. ${ }^{22,23}$ Amongst these guidelines, much debate exists regarding age at which screening should be initiated, frequency of screening, and modalities used to screen women in the general population for breast cancer. There is general agreement that women with a higher lifetime risk of breast cancer, such as that conferred by a $B R C A$ mutation, should undergo earlier, more frequent screening with consideration of additional imaging modalities. A consolidated summary of current screening recommendations published by National Comprehensive Cancer Network (NCCN), American Cancer Society (ACS), American College of Radiology (ACR) and other national organizations for the asymptomatic, female, $B R C A$ mutation carrier includes the following ${ }^{22,24-26}$ (Table 1):

- Monthly breast self-exam (BSE) beginning at the age of 18 years

- Semiannual clinical breast exam (CBE) beginning at the age of 25 years

- Annual mammograms beginning at the age of 25-30 years or individualized based on the earliest age of cancer onset in the family

- Annual breast magnetic resonance imaging (MRI) beginning at the age of 25-30 years or individualized based on the earliest age of cancer onset in the family 
Table I Surveillance recommendations for the asymptomatic BRCA mutation carrier

\begin{tabular}{|c|c|c|c|c|}
\hline & Screening modality & Age to initiate $(y)$ & Frequency & Notes \\
\hline \multicolumn{5}{|c|}{ Recommended screening } \\
\hline \multirow[t]{4}{*}{ Breast (female) } & BSE & 18 & Monthly & Mammogram and MRI initiated at age $25-30$ \\
\hline & $\mathrm{CBE}$ & 25 & Semiannual & or individualized based on the earliest age of \\
\hline & Mammogram & $25-30$ & Annual & cancer onset in the family \\
\hline & MRI & $25-30$ & Annual & \\
\hline \multirow[t]{3}{*}{ Breast (male) } & BSE & & Monthly & Annual mammogram with presence of \\
\hline & $\mathrm{CBE}$ & & Semiannual & gynecomastia/parenchymal tissue \\
\hline & Mammogram & & Baseline (annual) & \\
\hline \multirow[t]{3}{*}{ Ovarian } & Pelvic exam & 35 & Semiannual & Studies performed concurrently. Initiation \\
\hline & TVU & 35 & Semiannual & age 35 or $5-10$ y earlier than youngest \\
\hline & CA- 125 & 35 & Semiannual & diagnosed family member \\
\hline \multirow[t]{2}{*}{ Prostate } & DRE & $40-50$ & Annual & \\
\hline & PSA & $40-50$ & Annual & \\
\hline \multicolumn{5}{|c|}{ Additional screening (investigational) } \\
\hline \multirow[t]{2}{*}{ Pancreatic } & Endoscopic & 50 & Annual & Initiation age 50 or 10 y earlier than \\
\hline & ultrasound & & & youngest diagnosed family member \\
\hline \multirow[t]{2}{*}{ Melanoma } & Skin exam & & Annual & \\
\hline & Ocular exam & & Annual & \\
\hline \multirow[t]{3}{*}{ Colorectal } & FOBT & 50 & Annual & Follow population screening guidelines \\
\hline & Sigmoidoscopy & 50 & Every 5 y & \\
\hline & or colonsocopy & & Every $10 y$ & \\
\hline
\end{tabular}

Abbreviations: BSE, breast self-exam; CBE, clinical breast exam; MRI, magnetic resonance imaging; CA, cancer antigen; TVU, transvaginal ultrasound; DRE, digital rectal exam; PSA, prostate-screening antigen; FOBT, fecal occult blood testing.

\section{BSE and CBE}

$\mathrm{BSE}$ and $\mathrm{CBE}$ played an important role in breast cancer detection prior to the advent of screening mammography practices. In recent years, some screening guidelines removed the recommendation for monthly BSE in women at average risk for breast cancer. A 2003 Cochrane Review of two, large clinical trials concluded that the routine practice of BSE does not improve breast cancer mortality rates and nearly doubles the negative breast biopsy rate. ${ }^{27}$ Despite these data, the ACS continues to advocate for the practice of BSE in high-risk women. ${ }^{22,26}$ Two, recently published, single-institution studies demonstrated support for BSE as an important means of initial tumor detection. ${ }^{28,29} \mathrm{~A}$ retrospective study by Samphao et $\mathrm{a}^{28}$ concluded that of 628 women aged $<40$ years diagnosed with breast cancer ( $10 \%$ were $B R C A$ mutation carriers), $71 \%$ of tumors were initially detected by BSE. Similarly, a prospective study conducted by Wilke et $\mathrm{al}^{29}$ looked at 147 women undergoing high-risk surveillance. BSE was the most common initial method for detection of a mass in this study, exceeding the detection rate achieved by MRI. ${ }^{29}$ Of the 24 masses detected by BSE in this study, 6 (25\%) were confirmed cancers. ${ }^{29} \mathrm{BSE}$ in the high-risk population may be beneficial in detecting interval cancers. It represents a cost-effective, empowering, noninvasive technique to increase awareness of breast composition in these high-risk women.
The current value of $\mathrm{CBE}$ in the average-risk population is also controversial. The highest reported sensitivity of CBE in the literature is $54 \%$ when utilized in women of average population risk. ${ }^{30}$ As with BSE, there is limited evidence of a mortality benefit to CBE alone. With improvements in imaging technology, detection of occult disease by CBE may become less frequent amongst the general population. Conversely, $B R C A$ mutation carriers are likely to be younger with denser breast tissue. Dense breast tissue is an independent risk factor for breast cancer with a reported 2-to 6-fold increase in relative risk. ${ }^{31-33}$ Mammography sensitivity is known to diminish with increasing breast tissue density. The fast growth rate of $B R C A$-related cancers may lead to a higher interval detection rate by physical exam in the highrisk patient population. ${ }^{34}$

\section{Mammography and MRI}

Most national guidelines support the initiation of annual screening mammograms for the general population at age $40 .{ }^{22,35}$ While expert opinion recommends early initiation of imaging in high-risk women, there is a paucity of evidencebased data to support this recommendation. The quality of mammography as a screening tool in women of younger ages remains uncertain. As previously discussed, the sensitivity and specificity of mammography are recognized to be inversely related to breast tissue density. In addition to efficacy, there 
are safety concerns with earlier initiation of mammography screening. While the risk of radiation-induced breast cancer is low in the general population, the risk associated with a younger age at initial exposure, greater cumulative lifetime exposure, and increased chromosomal radiosensitivity in $B R C A$ mutation carriers may be clinically significant. ${ }^{26,36,37}$ The disadvantages of lower sensitivity and higher ionizing radiation risk with surveillance mammograms in young $B R C A$ mutation carriers has led to the investigation and support of other imaging modalities such as ultrasound and MRI.

In 2003, the ACS issued their recommendation for annual MRI screening as an adjunct to mammography in the high-risk population. ${ }^{26,38}$ This recommendation received additional endorsement from the ACR. ${ }^{25,26} \mathrm{~A}$ number of prospective studies demonstrated an increased rate of breast cancer detection through MRI screening in women at high risk. ${ }^{38,39}$ These studies reported MRI screening sensitivities that approach twice those achieved by mammogram alone. ${ }^{38,39}$ However, current recommendations emphasize that MRI should be used as an adjunct not as a replacement for mammography in the screening setting. ${ }^{25}$ Arguments against the use of screening MRI have included cost, limited patient access, poorer detection of ductal carcinoma in situ, and lower specificity with resultant higher, falsepositive biopsy rates. ${ }^{25,26,40}$ The perceived weakness of MRI screening may be abating as experience, technology, availability, and universal reporting criteria improve. More recent investigations demonstrate higher sensitivities and positive predictive values for MRI in a high-risk screening population. ${ }^{41,42}$ A prospective, multicenter cohort study by Kuhl et $\mathrm{al}^{41}$ investigated the use of mammogram, ultrasound, and MRI, alone or in combination, for screening of familial breast cancer. In this study, 687 asymptomatic women at high genetic risk for breast cancer underwent screening imaging. ${ }^{41}$ The sensitivity of each individual or combination of modalities was assessed. ${ }^{41}$ The detection sensitivities of mammogram and MRI alone were 33\% and 93\% respectively. ${ }^{41}$ When used in combination, mammogram and MRI achieved a greater although not statistically significant sensitivity of $100 \%{ }^{41}$ The addition of ultrasound to MRI did not increase sensitivity compared to MRI alone. ${ }^{41}$ Results of a more contemporary, multicenter study, the EVA trial (EVAluation of imaging methods for the secondary prevention of familial breast cancer) were recently published by the same author. ${ }^{42}$ The EVA trial demonstrated further support for MRI over mammography. ${ }^{42}$ It also challenges the current recommendation for a combined screening technique, questioning whether screening mammography should still be utilized in the high-risk population. ${ }^{42}$

\section{When to start mammography and MRI screening}

Current guidelines have not established a single age to initiate screening. Consensus is to start screening at an earlier age (25-30 years) than women of average risk (40 years). Given the younger age of disease onset seen in women at risk for hereditary breast cancer, a recent study by Litton et $\mathrm{al}^{43}$ investigated the age of cancer diagnosis for successive generations of $B R C A$ mutation carriers. The study concluded that genetic anticipation does occur with successive generations of $B R C A$ carriers developing cancer at an earlier age. ${ }^{43}$ This finding was more pronounced amongst $B R C A 2$ mutation carriers. ${ }^{43}$ Cumulative risk amongst $B R C A 1$ carriers is estimated to be $3 \%$ by the age of 30 years and $19 \%$ by 40 years. ${ }^{44}$

\section{Timing of mammography and MRI}

There is no current consensus on the time interval between annual mammogram and MRI. Screening with these modalities is either done concurrently or done staggered by 6 months. The concurrent approach allows for correlation between the two imaging techniques. The perceived advantage to staggering modalities by 6 months is the shorter interval between imaging exams. Most of the studies investigating screening mammography and MRI published in the past decade performed these imaging techniques in a concurrent or short- interval (within 1 month) fashion. ${ }^{38,39,45-49}$ The interval cancer rate detected in many of these studies was $<10 \%{ }^{38,39,45-49}$ This relatively low, interval cancer, detection rate might suggest lack of benefit with a staggered approach. However, there are notable differences in the protocol design of these studies. No current evidence-based data are available to demonstrate the superiority of one timing scheme vs the other.

\section{When to stop screening}

No published recommendations provide an age or age range to consider discontinuing screening exams. Discontinuation of screening in an asymptomatic $B R C A$ carrier can most practically be considered when the comorbidities of the patient confer a life expectancy of $<5-7$ years..$^{25,50}$ Alternatively, it is logical to stop screening when no intervention would be pursued for an abnormal finding secondary to age or physical condition.

Additional research is needed to determine if there is any benefit to adjusting imaging modalities for different age ranges. Should all modalities be initiated or discontinued at the same time? The literature already questions the added value and potential harm of combination screening (mammography plus MRI) vs MRI alone in the young mutation carrier. ${ }^{42}$ Is it feasible to limit early screening to 
MRI and transition to mammogram as sensitivity improves with age and decreasing breast density? Additional research is needed to answer these questions.

\section{Other imaging modalities}

The most common imaging modality to be considered in addition to the screening mammogram and MRI in high-risk women is breast ultrasound. Breast ultrasound is typically employed as an adjunct to mammogram for targeted diagnostic evaluation of a focal, suspicious area. As a screening tool, whole breast ultrasound has the lowest sensitivity of the three imaging modalities. The sensitivity of screening breast ultrasound in the literature is $17 \%-33 \% .{ }^{51}$ Support for breast ultrasound screening initially stemmed from earlier screening studies in women at high risk or with dense breast tissue. ${ }^{52-55}$ However, ultrasound in combination with current mammogram plus MRI surveillance has not shown additional benefit. ${ }^{25}$ Therefore, the utility of screening ultrasound as an adjunct to mammogram may be limited to high-risk patients with contraindications or poor access to MRI.

Numerous other imaging modalities are currently under investigation. Modalities achieving US Food and Drug Administration approval include tomography, computed tomography-positron emission tomography, thermography, and scintimammography. To date, none of these imaging techniques achieved evidence-based support or expert consensus for screening in the asymptomatic $B R C A$ mutation carrier.

\section{Ovarian cancer}

Unlike breast cancer, there is no recommended ovarian cancer screening for the general population. Despite a low incidence of $1.4 \%$, ovarian cancer remains the fourth leading cause of death in American women. Early stages of ovarian cancer are often asymptomatic. Consequently, the majority of women present with late-stage disease. Investigative efforts to establish effective screening strategies for earlier detection and mortality reduction have been unyielding. Most prior studies examined the use of annual transvaginal ultrasound (TVU) and CA-125 testing in both average and high-risk populations. Two studies by van Nagell et $\mathrm{al}^{56,57}$ reported a decrease in stage at detection and ovarian cancer mortality with TVU. These studies also reported superior sensitivity and specificity in the high-risk vs average-risk population with TVU and CA-125 levels. ${ }^{56,57}$ A specificity of $22.7 \%$ was demonstrated with a single abnormal result, but an increase in specificity to $90.9 \%$ with repeatedly abnormal test results. ${ }^{56,57}$ Those arguing against TVU and CA-125 testing cite low positive predictive values, the high cost of a false-positive, exploratory laparotomy, and failure of TVU to detect primary peritoneal cancers or ovarian malignancy with normal ovarian size. ${ }^{56-58}$ However, given the $10 \%-45 \%$ lifetime risk for ovarian cancer in BRCA mutation carriers, ${ }^{11,12,17,18}$ additional consideration is given to ovarian cancer screening by TVU and CA-125 testing. While the risk-reducing prophylactic oophorectomy is more effective in preventing ovarian cancer in these women, some may not opt to pursue this intervention until after their childbearing years. Without more effective screening methods available, TVU and CA-125 levels continue to be recommended and endorsed by national organizations for women at high risk for hereditary breast and ovarian syndromes. ${ }^{24}$ Current NCCN screening guidelines for BRCA mutation carriers not undergoing prophylactic oophorectomy include the following ${ }^{24}$ (Table 1):

- Semiannual concurrent pelvic exam, TVU, and CA-125 antigen determination beginning at the age of 35 years or 5-10 years earlier than the youngest family member diagnosed with ovarian cancer

\section{Male breast cancer and prostate cancer}

Cancer risk for male $B R C A$ mutation carriers is less well defined. Fewer men have pursued $B R C A$ testing. Consequently, there are fewer studies investigating cancer risk attributable to $B R C A 1$ and $B R C A 2$ in men. $B R C A$ mutations in the male population are reported to increase risk for breast, prostate, pancreatic, colon, melanoma, stomach, and other cancers. Phenotypic expression is thought to be variable amongst the two genes and various patient subpopulations. However, these differences are not well defined. As a result, there are few established screening recommendations for male carriers. Recommendations are limited to breast and prostate screening and do not distinguish between $B R C A 1$ vs $B R C A 2$ gene mutations carriers. Current NCCN guidelines include the following ${ }^{24}$ (Table 1):

- Monthly BSE

- Semiannual CBE

- Baseline mammogram followed by annual mammogram in the presence of gynecomastia or noted parenchymal tissue

- Population screening guidelines for prostate cancer beginning at the age of 40-50 years

- Digital rectal exam (DRE)

- Prostate screening antigen (PSA) testing

The literature suggests that BRCA mutations account for at least $20 \%$ of male breast cancer cases, with a higher phenotypic expression in $B R C A 2$ carriers. ${ }^{59}$ Stage per stage female and male breast cancer is equivalent in prognosis. The later stage of presentation for male breast cancer cases portends a worse overall prognosis. ${ }^{60}$ This may justify the 
recommendation to follow male carriers with mammography in addition to exam, especially in the presence of appreciable breast volume.

Prostate cancer is the leading cancer diagnosis amongst the male population in the United States. Guidelines for screening in the general population were recently updated by the ACS in $2010 .^{61}$ Earlier stages of detection and decreasing mortality in prostate cancer have been observed since the inception of PSA testing. Controversy and uncertainty remains as to whether PSA testing results in overdiagnosis and overtreatment of prostate cancers that would otherwise have low clinical impact. The benefit of DRE in addition to PSA testing is even less certain. At best, DRE increases cancer detection rates by $17 \% .^{62}$ Consequently, the updated ACS guidelines emphasize the need for shared and informed decision-making prior to the initiation and continuation of prostate screening in the general population. ${ }^{61}$ Given the risk of prostate cancer is increased 3-to 5-fold in male $B R C A$ mutation carriers, ${ }^{21,63}$ this population is encouraged to follow the ACS guidelines for men at high risk. The ACS recommends initiating annual DRE and PSA testing at the age of 40 years. ${ }^{61}$ Similar to the phenotypic expression of male breast cancer, the Breast Cancer Linkage Consortium reports a greater relative risk $(\mathrm{RR})$ for prostate cancer amongst $B R C A 2$ carrier $(\mathrm{RR}=7.3) .{ }^{63}$ None of the current guidelines further delineate prostate screening by specific gene mutation or age. The recommended time to discontinue prostate screening is at life expectancy $<10$ years. ${ }^{60}$

\section{Other associated cancer screening}

Mutations in the tumor suppressor genes $B R C A 1$ and $B R C A 2$ place male and female carriers at increased risk for a number of other cancers, notably pancreatic, melanoma, colorectal, and other gastrointestinal tumors. Further research is needed to define the association of specific $B R C A$ mutations with these cancers. No expert consensus or evidence-based guidelines exist regarding screening for these cancers. Some literature and investigational studies support considering the following additional surveillance modalities ${ }^{59,64-66}$ (Table 1):

- Pancreatic: annual endoscopic ultrasound, beginning at the age of 50 years or 10 years prior to earliest pancreatic cancer diagnosis in family ${ }^{64-65}$

- Melanoma: annual full body skin and ocular exam ${ }^{59}$

- Colorectal: population screening guidelines, beginning at the age of 50 years and continuing until 75 years old - Annual fecal occult blood testing
- Sigmoidoscopy every 5 years or colonoscopy every 10 years $^{66}$

\section{Risk reduction Behavioral modifications}

\section{Body mass index}

Obesity and postmenopausal weight gain have been associated with an increased risk of sporadic breast cancer. A single study of French-Canadian families with $B R C A$ mutations has addressed these risk factors for $B R C A$-related breast cancer risk. ${ }^{67}$ This case-control study of 80 families examined dietary intake, physical activity, and weight gain. ${ }^{67}$ Findings demonstrated an increased risk of breast cancer associated with increased total energy intake and weight gain. ${ }^{67}$ Those in the highest total energy intake tertile had a breast cancer odds ratio (OR) of 2.76 (95\% confidence interval [CI]: 1.10-7.02; $P=0.026)$ as compared with those in the lowest tertile of intake. ${ }^{67}$ Weight gain after the age of 18 years and after the age of 30 years were associated with OR of 4.64 (95\% CI: 1.52-14.12; $P=0.011)$ and 4.11 (95\% CI: 1.46-11.56; $P=0.013)$, respectively. ${ }^{67}$ This study also concluded that women who consumed $>2239 \mathrm{kcal} /$ day were at greater risk of $B R C A$-related breast cancer compared to women who consumed $<1724 \mathrm{kcal} /$ day ${ }^{67}$ This finding was independent of age, BMI, and participation in sports or exercise, suggesting that caloric restriction may be related to a reduction in $B R C A$-related breast cancer risk. ${ }^{67}$ Further investigations by the same author examined the impact of specific diets and foods on breast cancer risk. ${ }^{68} \mathrm{~A}$ diet rich in different types of vegetables and fruits was found to correlate with a decreased risk of breast cancer. ${ }^{69}$

\section{Lifestyle}

Collaborative research conducted by the Breast Cancer Family Registry (a consortium of research groups in the United States, Australia, and Canada), the Kathleen Cunningham Consortium for Research into Familial Breast Cancer (Australia and New Zealand), and the Ontario Cancer Genetics Network (Ontario, Canada) have improved the understanding of how lifestyle may impact breast cancer risk among $B R C A$ mutation positive women. ${ }^{70}$ Data collected from case-control studies reported no evidence of increased breast cancer risk with alcohol consumption among carriers of $B R C A 1$ and $B R C A 2$ mutation who are aged $<50$ years. $^{70}$ However, there was an increased risk of breast cancer before the age of 50 years in mutation carriers who smoke. ${ }^{70} \mathrm{Com}-$ pared to nonsmokers, the OR for risk of breast cancer in 
females with $\geq 5$ pack-years of smoking was 2.3 for $B R C A 1$ carriers (95\% CI: 1.6-3.6) and 2.6 (95\% CI: 1.8-3.9) for $B R C A 2$ carriers. $^{71}$

\section{Oral contraception}

Oral contraceptive use by $B R C A$ mutation carriers has been associated with a decrease in ovarian cancer risk. ${ }^{72-73}$ However, the impact of oral contraceptive use on the risk of breast cancer is less clear. A case-control study of $B R C A$ mutation carriers aged $<50$ years found no evidence of increased breast cancer risk amongst those who used oral contraceptives for at least one year. ${ }^{74}$ For $B R C A 1$ mutation positive carriers, there was no association between longer duration of use and breast cancer risk. ${ }^{74}$ Conversely, an increased breast cancer risk was observed in BRCA2 mutation carriers who used oral contraceptives for at least 5 years $(\mathrm{OR}=2.06: 95 \% \mathrm{CI}$ : $1.08-3.94) .{ }^{74}$ Other investigators have not identified an association between oral contraceptive use and increased breast cancer risk. ${ }^{75}$ The use of current, low dose, contraceptive formulations in $B R C A$ mutation carriers can be supported by the lack of evidence for increased early-onset breast cancer risk and the known benefit of ovarian cancer risk reduction.

\section{Chemoprevention}

Two, large chemoprevention studies conducted by the National Surgical Adjuvant Breast and Bowel Project demonstrate that tamoxifen and raloxifene are effective in lowering the risk for developing an estrogen receptor (ER)-positive breast cancer in women at high risk by Gail model assessment. ${ }^{76}$ While there are no data on the impact of raloxifene on breast cancer risk for $B R C A$ mutation carriers, a subset analysis of the original prevention trial was performed to determine whether there is a benefit to tamoxifen over placebo in women with $B R C A$ mutations. ${ }^{77,78}$ Genetic testing was performed on the 288 women in the trial who developed breast cancer. ${ }^{77}$ Only 19 of the 288 patients were found to carry a $B R C A 1$ or $B R C A 2$ mutation. ${ }^{77}$ Of the 8 patients who carried a $B R C A 1$ mutation, 5 received tamoxifen and 3 received placebo, yielding a risk ratio for tamoxifen of 1.67 (95\% CI: $0.32-10.70) .{ }^{77} \mathrm{Of}$ the 11 patients who carried a BRCA2 mutation, 3 received tamoxifen and 8 received placebo, yielding a risk ratio for tamoxifen of 0.38 (95\% CI: 0.06-1.56). ${ }^{77}$ The differential effect of tamoxifen in reducing risk of breast cancer amongst $B R C A 1$ and $B R C A 2$ carriers has been hypothesized to relate to the increased frequency of ER-negative cancers arising in the setting of $B R C A 1$ mutations and ER-positive cancers in the setting of $B R C A 2$ mutations. ${ }^{20}$
Additional research has investigated the role of tamoxifen in risk reduction for contralateral breast cancer. Retrospective reviews of the impact of tamoxifen on contralateral breast cancer risk in patients with a personal history of unilateral, hormone receptor positive, breast cancer support its efficacy as a protective agent. A case-control study conducted by the Hereditary Breast Cancer Clinical Study Group found tamoxifen protective against contralateral breast cancer for both $B R C A 1$ and BRCA2 mutation positive patients. ${ }^{79}$ The OR for contralateral breast cancer for $B R C A 1$-positive patients on tamoxifen was 0.38 (95\% CI: $0.19-0.74) .{ }^{79}$ For $B R C A 2-$ positive patients, the OR was 0.63 (95\% CI: $0.20-1.50) .{ }^{79}$ In this study, the benefit of tamoxifen appeared to be independent of oophorectomy. ${ }^{79}$ A second case-control study confirmed the protective benefit of tamoxifen in preventing a contralateral breast cancer in women starting tamoxifen after diagnosis of their first breast cancer. ${ }^{80}$ The multivariant OR for contralateral breast cancer associated with tamoxifen use was 0.50 (95\% CI: $0.30-0.85)$ in $B R C A 1$ mutation carriers and 0.42 (95\% CI: 0.17-1.02) in BRCA2 mutation carriers. ${ }^{81}$ However, in this study the benefit of tamoxifen was not seen in women who had undergone prior oophorectomy. ${ }^{81}$

\section{Prophylactic surgery}

Risk reduction can also be achieved through removal of the "at risk" tissue by prophylactic bilateral mastectomy or bilateral salpingo-oophorectomy. While these procedures represent the most aggressive strategy, they are the most effective at reducing breast and ovarian cancer risk. Consideration of prophylactic surgery is appropriate for both $B R C A 1$ and $B R C A 2$ mutation carriers.

\section{Prophylactic bilateral mastectomy}

Prophylactic bilateral mastectomies (PBM) exhibit an $85 \%-100 \%$ reduction in breast cancer risk in retrospective and prospective studies. ${ }^{81,82}$ Similar findings were reported in studies conducted in known female $B R C A$ mutation carriers. ${ }^{81,83}$ The Prevention and Observation of Surgical Endpoints study is the largest, prospective cohort study to look at the risk reduction benefit of PBM in women with $B R C A$ mutations. ${ }^{84}$ Results of this trial supported a $90 \%$ reduction in risk with breast cancer being diagnosed in $2 \%$ of $B R C A$ carriers undergoing PBM compared to $49 \%$ of carrier who did not. ${ }^{84}$ Risk reduction was increased to $95 \%$ in women undergoing prior or concurrent prophylactic bilateral oophorectomy. ${ }^{84}$ To date, no randomized control trial has been conducted to examine the benefit of PBM. It is unlikely such a trial will be carried out 
given the probable disinterest of patients to be randomized to the procedure, the existing support for the efficacy of PBM, and the long follow-up time necessary for such a study.

Discussion of the risks and benefits of PBM requires open dialogue between patient and provider and must include type of surgery, reconstruction options, related risks, and potential psychological effects. Until recently, the majority of PBM were performed using a simple or skin-sparing mastectomy technique, removing the nipple areola complex with all the underlying breast parenchyma. More recently, a nipplesparing approach has gained acceptance in the prophylactic mastectomy setting. Using a periareolar or inframammary incision, the breast parenchyma is removed with preservation of the nipple areolar complex. Breast tissue within the nipple is cored out to minimize the amount of breast tissue left behind. This technique is often best for women desiring reconstruction with smaller breast volume and minimal ptosis. Reconstruction options include immediate vs delayed and implant vs an array of autologous tissue flaps. Selection of the optimal reconstructive procedure must take into account patient choice, body habitus, and comorbities. Risks associated with PBM can relate to the invasiveness of the procedures. Short-term complications include bleeding, seroma formation, and infection. It is not technically feasible to provide $100 \%$ risk reduction with this procedure. The risk of recurrence may be higher with nipple-sparing techniques that have the potential for greater amounts of residual breast tissue. The psychological impact of PBM must also be taken into consideration. Current data on the negative impact of PBM on body image are limited. Some data indicate that PBM improves quality of life by reducing emotional concern for developing breast cancer. ${ }^{85}$

\section{Prophylactic bilateral salpingo-oophorectomy}

Prophylactic bilateral salpingo-oophorectomy (PBSO) demonstrates a similar $80 \%-90 \%$ reduction in ovarian cancer risk for mutation carriers. ${ }^{86}$ An added benefit to PBSO is the $50 \%$ observed reduction in breast cancer when it is performed in premenopausal women. ${ }^{87,88}$ Breast cancer risk reduction is attributed to the beneficial effect of hormone deprivation. ${ }^{88,89}$ A recent meta-analysis conducted by Rebbeck et $\mathrm{l}^{86}$ pooled hazard ratio (HR) results from 10 studies investigating the reduction in risk associated with $\mathrm{PBSO}$ in $B R C A 1$ and $B R C A 2$ mutation carriers. Compiled results demonstrated a significant risk reduction with $\mathrm{PBSO}$ for both breast cancer $(\mathrm{HR}=0.49)$ and ovarian cancer $(\mathrm{HR}=0.21)$ in premenopausal $B R C A$ mutation carriers. ${ }^{86}$ No difference was observed in breast cancer risk reduction between $B R C A 1$ $(\mathrm{HR}=0.47)$ and $B R C A 2(\mathrm{HR}=0.47)$ carriers with PBSO.$^{86}$
However, a recent prospective cohort study by Kauff et $\mathrm{al}^{90}$ concluded that the risk reduction associated with PBSO may be greater in the $B R C A 1$ carrier. The equivalent or superior reduction achieved in BRCA1 carriers may be counterintuitive when considering the association of $B R C A 1$ mutation to ER-negative breast cancers. Perhaps more intuitive is the inverse relationship suggested between breast cancer risk reduction with $\mathrm{PBSO}$ and age. Eisen et $\mathrm{al}^{91}$ investigated the difference in HR for carriers undergoing $\mathrm{PBSO}$ when aged $<40$ years, $41-50$ years, and $>50$. Negligible risk reduction was found with PBSO in $B R C A$ carriers aged $>50$ years compared to a $50 \%$ reduction in carriers aged $41-50$ years, and a $64 \%$ reduction in carriers aged $<40$ years. ${ }^{91}$ Given these findings, the NCCN recommends consideration of PBSO in BRCA1 and BRCA2 carriers aged 35-40 years, at completion of child bearing, or based on the age of the earliest family member diagnosed with ovarian cancer. ${ }^{24}$

In addition to the increased risk for ovarian cancers, mutations in the $B R C A$ genes increase the risk of fallopian and peritoneal cancers of common epithelial origin. For this reason, PBSO includes removal of both ovaries and fallopian tubes. The addition of a hysterectomy is advocated by some providers on the basis of residual epithelial fallopian tube tissue within the wall of the uterus. ${ }^{92,93}$ With the advent of minimally invasive surgery, the majority of PBSO are performed using a laparoscopic technique. NCCN guidelines additionally recommend that peritoneal washings be obtained at the time of surgery and fine sectioning be used in the pathologic examination of the ovaries and fallopian tubes. ${ }^{24}$

Patients should be appropriately informed about both the operative and long-term risks related to risk-reducing, bilateral salpingo-oophorectomy. As with mastectomy, it is not feasible to remove all of the cells at risk even with inclusion of a hysterectomy. The reported risk of $B R C A$-associated, primary peritoneal carcinoma is up to $4.3 \%{ }^{86-88} \mathrm{PBSO}$ limits reproduction and can precipitate early menopausal symptoms in younger women. Early menopause may increase the risks of osteopenia, osteoporosis, and cardiovascular disease. While data are limited, short-term administration of hormone replacement therapy does appear to be safe..$^{94}$

\section{Risk-reducing surgery: who, when, and what}

The optimal timing of prophylactic surgery for an asymptomatic $B R C A$ mutation carrier is highly personal. The earlier onset of disease seen in mutation carriers would support recommending these procedures at a younger age. However, efforts to optimize risk reduction in the younger age group may conflict with the negative impact of undergoing invasive procedures during or near childbearing years. It appears safe to delay PBSO until completion of parturition. Overall, PBSO 
is pursued more often than PBM amongst $B R C A$ mutation carriers. ${ }^{95-97}$ An increased acceptance of PBSO over PBM may relate to the "double" benefit effect of reducing breast and ovarian cancer risk, the less effective screening for ovarian cancer, the reduced invasiveness (shorter postoperative recovery, fewer operative wound complications) of the procedure, and the lesser impact it has on external body image. ${ }^{98}$

Two studies by Beattie et $\mathrm{al}^{98}$ in 2009 and Scheuer et $\mathrm{al}^{99}$ in 2002 investigated the adoption of prophylactic procedures, time from genetic testing to operative intervention, and predictors for undergoing risk reducing surgeries amongst $B R C A$ carriers. Scheuer et $\mathrm{a} \mathrm{l}^{99}$ found that the $14.9 \%$ of carriers with at risk tissue chose to undergo PBM and $50.3 \%$ opted for PBSO. Median time to surgery from receipt of genetic test results was 5.3 months for PBM and 3.4 months for PBSO. ${ }^{99}$ Patients selecting PBM were younger and more likely to have first and second degree relatives affected by breast or ovarian cancer as compared with those opting for surveillance. ${ }^{99}$ Women choosing PBSO were 5 years older ( 47 vs 42 years) and more likely to have a history of breast cancer than those declining PBSO ${ }^{99} \mathrm{~A}$ contemporary study by Beattie et al ${ }^{98}$ complements Scheuer's findings. In this study, $23 \%$ of carriers pursued PBM and $51 \%$ underwent PBSO. ${ }^{98}$ Both procedures were performed at a median of 4 months from patient knowledge of positive $B R C A$ test results. ${ }^{98}$ Predictors for utilization of risk reducing surgery included age $<60$ years, prior history of breast or ovarian cancer, and concurrent or prior acceptance of the alternative prophylactic procedure. ${ }^{98}$

\section{Conclusion}

The optimal management approach for early detection and cancer prevention in the asymptomatic $B R C A$ carrier continues to evolve. This review presents the guidelines and data supporting the development of a personalized strategy for each asymptomatic $B R C A$ mutation carrier. Many of the recommendations are based on expert opinion as it is difficult to conduct randomized control trials in this population. Optimizing management strategies requires knowledge of the benefits and limitations of the presented strategies, ongoing investigation with newer surveillance techniques and risk-reducing interventions, and informed decision-making between patient and provider.

\section{Disclosure}

The authors disclose no conflicts of interest.

\section{References}

1. Gayther SA, Warren W, Mazoyer S, et al. Germline mutations of the BRCA1 gene in breast and ovarian cancer families provide evidence for a genotype-phenotype correlation. Nat Genet. 1995;11(4):428-433.

2. Hall JM, Lee MK, Newman B, et al. Linkage of early-onset familial breast cancer to chromosome 17q21. Science. 1990;250(4988):1684-1689.
3. Wooster R, Neuhausen SL, Mangion J, et al. Localization of a breast cancer susceptibility gene, BRCA2, to chromosome 13q12-13. Science. 1994;265(5181):2088-2090

4. Claus EB, Schildkraut JM, Thompson WD, Risch NJ. The genetic attributable risk of breast and ovarian cancer. Cancer. 1996;77(11): 2318-2324.

5. Berliner JL, Fay AM. Risk assessment and genetic counseling for hereditary breast and ovarian cancer: recommendations of the National Society of Genetic Counselors. J Genet Couns. 2007;16(3): 241-260.

6. Foulkes WD. Inherited susceptibility to common cancers. $N$ Engl $J$ Med. 2008;359(20):2143-2153.

7. American College of Obstetricians and Gynecologists; ACOG Committee on Practice Bulletins - Gynecology; ACOG Committee on Genetics; Society of Gynecologic Oncologists. ACOG Practice Bulletin No. 103: hereditary breast and ovarian cancer syndrome. Obstet Gynecol. 2009;113(4):957-966

8. Whittemore AS. Risk of breast cancer in carriers of BRCA gene mutations. N Engl J Med. 1997;337(11):788-789.

9. Metcalfe KA, Poll A, Royer R, et al. Screening for founder mutations in BRCA1 and BRCA2 in unselected Jewish women. J Clin Oncol. 2010;28(3):387-391.

10. US Census Bureau. Available from: http://www.census.gov/popest/ national/national.html. Accessed June 26, 2010.

11. Whittemore AS, Gong G, Itnyre J. Prevalence and contribution of BRCA1 mutations in breast cancer and ovarian cancer: results from three U.S. population-based case-control studies of ovarian cancer. Am J Hum Genet. 1997;60(3):496-504.

12. Antoniou A, Pharoah PD, Narod S, et al. Average risks of breast and ovarian cancer associated with BRCA1 or BRCA2 mutations detected in case Series unselected for family history: a combined analysis of 22 studies. Am J Hum Genet. 2003;72(5):1117-1130.

13. Begg CB, Haile RW, Borg A, et al. Variation of breast cancer risk among BRCA1/2 carriers. JAMA. 2008;299(2):194-201.

14. Malone KE, Begg CB, Haile RW, et al. Population-based study of the risk of second primary contralateral breast cancer associated with carrying a mutation in BRCA1 or BRCA2. J Clin Oncol. 2010; 28(14):2404-2410.

15. Graeser MK, Engel C, Rhiem K, et al. Contralateral breast cancer risk in BRCA1 and BRCA2 mutation carriers. J Clin Oncol. 2009;27(35): 5887-5892.

16. Tai YC, Domchek S, Parmigiani G, Chen S. Breast cancer risk among male BRCA1 and BRCA2 mutation carriers. $J$ Natl Cancer Inst. 2007;99(23):1811-1814.

17. Brose MS, Rebbeck TR, Calzone KA, Stopfer JE, Nathanson KL, Weber BL. Cancer risk estimates for BRCA1 mutation carriers identified in a risk evaluation program. $J$ Natl Cancer Inst. 2002;94(18): $1365-1372$.

18. Risch HA, McLaughlin JR, Cole DE, et al. Population BRCA1 and BRCA2 mutation frequencies and cancer penetrances: a kincohort study in Ontario, Canada. J Natl Cancer Inst. 2006;98(23): 1694-1706.

19. Thompson D, Easton DF; for Breast Cancer Linkage Consortium. Cancer incidence in BRCA1 mutation carriers. J Natl Cancer Inst. 2002;94(18):1358-1365.

20. Ashworth A. Weber BL, Domcheck SM. Inherited genetic factors and breast cancer. In: Harris J Lippman ME, Morrow M, Osbourne CK, editors. Diseases of the Breast. Philadelphia, PA: Lippincott Williams and Wilkins; 2010.

21. Cancer risks in BRCA2 mutation carriers. The Breast Cancer Linkage Consortium. J Natl Cancer Inst. 1999;91(15):1310-1316.

22. American Cancer Society Guidelines for the Early Detection of Cancer. Available from http://www.cancer.org/healthy/findcancerearly/ cancerscreeningguidelines/american-cancer-society-guidelines-for-theearly-detection-of-cancer. Accessed June 6, 2010.

23. US Preventive Services Task Force. Screening for Breast Cancer. Available from http://www.uspreventiveservicestaskforce.org/uspstf/ uspsbrca.htm. Accessed July 15, 2010. 
24. Genetic/Familial High-Risk Assessment: Breast and Ovarian. NCCN Clinical Practice Guidelines in Oncology 2010; v.1.2010. Available from: http://www.nccn.org/professionals/physician_gls/pdf/ genetics_screening.pdf. Accessed July 9, 2010.

25. Lee CH, Dershaw DD, Kopans D, et al. Breast cancer screening with imaging: recommendations from the Society of Breast Imaging and the ACR on the use of mammography, breast MRI, breast ultrasound, and other technologies for the detection of clinically occult breast cancer. J Am Coll Radiol. 2010;7(1):18-27.

26. Smith RA, Saslow D, Sawyer KA, et al. American Cancer Society guidelines for breast cancer screening: update 2003. CA Cancer J Clin. 2003;53(3):141-169.

27. Kösters JP, Gøtzsche PC. Regular self-examination or clinical examination for early detection of breast cancer. Cochrane Database Syst Rev. 2003(Issue 2). Available from: http://www2.cochrane.org/reviews/en/ ab003373.html. Accessed June 26, 2010.

28. Samphao S, Wheeler AJ, Rafferty E, et al. Diagnosis of breast cancer in women age 40 and younger: delays in diagnosis result from underuse of genetic testing and breast imaging. Am J Surg. 2009;198(4):538-543.

29. Wilke LG, Broadwater G, Rabiner S, et al. Breast self-examination: defining a cohort still in need. Am J Surg. 2009;198(4):575-579.

30. Barton MB, Harris R, Fletcher SW. The rational clinical examination. Does this patient have breast cancer? The screening clinical breast examination: should it be done? How? JAMA. 1999;282(13):1270-1280.

31. McCormack VA, dos Santos Silva I. Breast density and parenchymal patterns as markers of breast cancer risk: a meta-analysis. Cancer Epidemiol Biomarkers Prev. 2006;15(6):1159-1169.

32. Harvey JA, Bovbjerg VE. Quantitative assessment of mammographic breast density: relationship with breast cancer risk. Radiology. 2004; 230(1):29-41.

33. Boyd NF, Guo H, Martin LJ, et al. Mammographic density and the risk and detection of breast cancer. N Engl J Med. 2007;356(3):227-236.

34. Samuel JC, Ollila DW. Prophylaxis and screening options: recommendations for young women with BRCA mutations. Breast Dis. 2005; 23:31-35.

35. National Cancer Institute Fact Sheet: Mammograms. Available from: http://www.cancer.gov/cancertopics/factsheet/detection/mammograms. Accessed June 15, 2010.

36. Ernestos B, Nikolaos P, Koulis G, et al. Increased chromosomal radiosensitivity in women carrying BRCA1/BRCA2 mutations assessed with the G2 assay. Int J Radiat Oncol Biol Phys. 2010;76(4):1199-1205.

37. Berrington de Gonzalez A, Berg CD, Visvanathan K, Robson M. Estimated risk of radiation-induced breast cancer from mammographic screening for young BRCA mutation carriers. J Natl Cancer Inst. 2009; 101(3):205-209.

38. Kriege M, Brekelmans CT, Boetes C, et al. Efficacy of MRI and mammography for breast-cancer screening in women with a familial or genetic predisposition. N Engl J Med. 2004;351(5):427-437.

39. Leach MO, Boggis CR, Dixon AK, et al. Screening with magnetic resonance imaging and mammography of a UK population at high familial risk of breast cancer: a prospective multicentre cohort study (MARIBS). Lancet. 2005;365(9473):1769-1778.

40. Elmore JG, Armstrong K, Lehman CD, Fletcher SW. Screening for breast cancer. JAMA. 2005;293(10):1245-1256.

41. Kuhl CK, Schrading S, Weigelt S, et al. Management recommendations for women at increased familial risk for breast cancer: results of a prospective national multimodality cohort study. J Clin Oncol. 2008; 26 Suppl 20:1500.

42. Kuhl C, Weigel S, Schrading S, et al. Prospective multicenter cohort study to refine management recommendations for women at elevated familial risk of breast cancer: the EVA trial. J Clin Oncol. 2010;28(9): 1450-1457.

43. Litton JK, Ready K, Chen H, Gutierrez-Barrera A, et al. Earlier age of onset of $B R C A$ mutation-related cancers in subsequent generations [abstract]. ASCO: 2009 Breast Cancer Symposium. 2009.

44. Easton DF, Ford D, Bishop DT. Breast and ovarian cancer incidence in BRCA1-mutation carriers. Breast Cancer Linkage Consortium. Am J Hum Genet. 1995;56(1):265-271.
45. Lehman CD, Blume JD, Weatherall $\mathrm{P}$, et al. Screening women at high risk for breast cancer with mammography and magnetic resonance imaging. Cancer. 2005;103(9):1898-1905.

46. Dent R, Warner E. Screening for hereditary breast cancer. Semin Oncol. 2007;34(5):392-400.

47. Kuhl CK, Schrading S, Leutner CC, et al. Mammography, breast ultrasound, and magnetic resonance imaging for surveillance of women at high familial risk for breast cancer. J Clin Oncol. 2005;23(33):8469-8476.

48. Warner E, Plewes DB, Hill KA, et al. Surveillance of BRCA1 and BRCA2 mutation carriers with magnetic resonance imaging, ultrasound, mammography, and clinical breast examination. JAMA. 2004;292(11): 1317-1325.

49. Podo F, Sardanelli F, Canese R, et al. The Italian multi-centre project on evaluation of MRI and other imaging modalities in early detection of breast cancer in subjects at high genetic risk. J Exp Clin Cancer Res. 2002;21 Suppl 3:115-124.

50. Kerlikowske K, Salzmann P, Phillips KA, Cauley JA, Cummings SR. Continuing screening mammography in women aged 70 to 79 years: impact on life expectancy and cost-effectiveness. JAMA. 1999; 282(22):2156-2163.

51. Weinstein SP, Localio AR, Conant EF, Rosen M, Thomas KM, Schnall MD. Multimodality screening of high-risk women: a prospective cohort study. J Clin Oncol. 2009;27(36):6124-6128.

52. Gordon PB, Goldenberg SL. Malignant breast masses detected only by ultrasound. A retrospective review. Cancer. 1995;76(4):626-630.

53. Kolb TM, Lichy J, Newhouse JH. Occult cancer in women with dense breasts: detection with screening US - diagnostic yield and tumor characteristics. Radiology. 1998;207(1):191-199.

54. Buchberger W, DeKoekkoek-Doll P, Springer P, Obrist P, Dunser M. Incidental findings on sonography of the breast: clinical significance and diagnostic workup. AJR Am J Roentgenol. 1999;173(4):921-927.

55. Berg WA, Blume JD, Cormack JB, et al. Combined screening with ultrasound and mammography vs mammography alone in women at elevated risk of breast cancer. JAMA. 2008;299(18):2151-2163.

56. van Nagell JR Jr, DePriest PD, Ueland FR, et al. Ovarian cancer screening with annual transvaginal sonography: findings of 25,000 women screened. Cancer. 2007;109(9):1887-1896.

57. van Nagell JR Jr, DePriest PD, Reedy MB, et al. The efficacy of transvaginal sonographic screening in asymptomatic women at risk for ovarian cancer. Gynecol Oncol. 2000;77(3):350-356.

58. Woodward ER, Sleightholme HV, Considine AM, Williamson S, McHugo JM, Cruger DG. Annual surveillance by CA125 and transvaginal ultrasound for ovarian cancer in both high-risk and population risk women is ineffective. BJOG. 2007;114(12):1500-1509.

59. Liede A, Karlan BY, Narod SA. Cancer risks for male carriers of germline mutations in BRCA1 or BRCA2: a review of the literature. J Clin Oncol. 2004;22(4):735-742.

60. SEER Database: Surveillance, Epidemiology and End Results (SEER). 2003. Available from: http://seer.cancer.gov/. Accessed July $9,2010$.

61. Wolf AM, Wender RC, Etzioni RB, et al; for American Cancer Society Prostate Cancer Advisory Committee. American Cancer Society guideline for the early detection of prostate cancer: update 2010. CA Cancer J Clin. 2010;60(2):70-98.

62. Schroder FH, van der Maas P, Beemsterboer P, et al. Evaluation of the digital rectal examination as a screening test for prostate cancer. Rotterdam section of the European Randomized Study of Screening for Prostate Cancer. J Natl Cancer Inst. 1998;90(23):1817-1823.

63. Ford D, Easton DF, Bishop DT, Narod SA, Goldgar DE. Risks of cancer in BRCA1-mutation carriers. Breast Cancer Linkage Consortium. Lancet. 1994;343(8899):692-695.

64. Brentnall TA. Cancer surveillance of patients from familial pancreatic cancer kindreds. Med Clin North Am. 2000;84(3):707-718.

65. Canto MI, Goggins M, Yeo CJ, et al. Screening for pancreatic neoplasia in high-risk individuals: an EUS-based approach. Clin Gastroenterol Hepatol. 2004;2(7):606-621. 
66. US Preventive Services Task Force. Screening for Colorectal Cancer: US. Preventive Services Task Force Recommendation Statement. AHRQ Publication 08-05124-EF-05123. Available from: http://www.ahrq.gov/ clinic/uspstf08/colocancer/colors.htm. Accessed July 2, 2010.

67. Nkondjock A, Robidoux A, Paredes Y, Narod SA, Ghadirian P. Diet, lifestyle and BRCA-related breast cancer risk among French-Canadians. Breast Cancer Res Treat. 2006;98(3):285-294.

68. Nkondjock A, Ghadirian P. Diet quality and BRCA-associated breast cancer risk. Breast Cancer Res Treat. 2007;103(3):361-369.

69. Ghadirian P, Narod S, Fafard E, Costa M, Robidoux A, Nkondjock A. Breast cancer risk in relation to the joint effect of BRCA mutations and diet diversity. Breast Cancer Res Treat. 2009;117(2):417-422.

70. McGuire V, John EM, Felberg A, et al. No increased risk of breast cancer associated with alcohol consumption among carriers of BRCA1 and BRCA2 mutations ages $<50$ years. Cancer Epidemiol Biomarkers Prev. 2006;15(8):1565-1567.

71. Smoking and risk of breast cancer in carriers of mutations in BRCA1 or BRCA2 aged less than 50 years. Breast Cancer Res Treat. 2008;109(1): $67-75$.

72. Narod SA, Ford D, Devilee P, et al. An evaluation of genetic heterogeneity in 145 breast-ovarian cancer families. Breast Cancer Linkage Consortium. Am J Hum Genet. 1995;56(1):254-264.

73. Whittemore AS, Balise RR, Pharoah PD, et al. Oral contraceptive use and ovarian cancer risk among carriers of BRCA1 or BRCA2 mutations Br J Cancer. 2004;91(11):1911-1915.

74. Haile RW, Thomas DC, McGuire V, et al. BRCA1 and BRCA2 mutation carriers, oral contraceptive use, and breast cancer before age 50. Cancer Epidemiol Biomarkers Prev. 2006;15(10):1863-1870.

75. Milne RL, Knight JA, John EM, et al. Oral contraceptive use and risk of early-onset breast cancer in carriers and noncarriers of BRCA1 and BRCA2 mutations. Cancer Epidemiol Biomarkers Prev. 2005; 14(2):350-356.

76. Wickerham DL, Costantino JP, Vogel VG, et al. The use of tamoxifen and raloxifene for the prevention of breast cancer. Recent Results Cancer Res. 2009;181:113-119.

77. King MC, Wieand S, Hale K, et al. Tamoxifen and breast cancer incidence among women with inherited mutations in BRCA1 and BRCA2: National Surgical Adjuvant Breast and Bowel Project (NSABP-P1) Breast Cancer Prevention Trial. JAMA. 2001;286(18):2251-2256.

78. Fisher B, Costantino JP, Wickerham DL, et al. Tamoxifen for prevention of breast cancer: report of the National Surgical Adjuvant Breast and Bowel Project P-1 Study. J Natl Cancer Inst. 1998;90(18):1371-1388.

79. Narod SA, Brunet JS, Ghadirian P, et al. Tamoxifen and risk of contralateral breast cancer in BRCA1 and BRCA2 mutation carriers: a case-control study. Hereditary Breast Cancer Clinical Study Group. Lancet. 2000;356(9245):1876-1881.

80. Gronwald J, Tung N, Foulkes WD, et al; for Hereditary Breast Cancer Clinical Study Group. Tamoxifen and contralateral breast cancer in BRCA1 and BRCA2 carriers: an update. Int J Cancer. 2006;118(9): 2281-2284.

81. Hartmann LC, Sellers TA, Schaid DJ, et al. Efficacy of bilateral prophylactic mastectomy in BRCA1 and BRCA2 gene mutation carriers. J Natl Cancer Inst. 2001;93(21):1633-1637.

82. Hartmann LC, Schaid DJ, Woods JE, et al. Efficacy of bilateral prophylactic mastectomy in women with a family history of breast cancer. $N$ Engl J Med. 1999;340(2):77-84.
83. Meijers-Heijboer H, van Geel B, van Putten WL, et al. Breast cancer after prophylactic bilateral mastectomy in women with a BRCA1 or BRCA2 mutation. $N$ Engl J Med. 2001;345(3):159-164.

84. Rebbeck TR, Friebel T, Lynch HT, et al. Bilateral prophylactic mastectomy reduces breast cancer risk in BRCA1 and BRCA2 mutation carriers: the PROSE Study Group. J Clin Oncol. 2004;22(6): 1055-1062.

85. Frost MH, Schaid DJ, Sellers TA, et al. Long-term satisfaction and psychological and social function following bilateral prophylactic mastectomy. JAMA. 2000;284(3):319-324.

86. Rebbeck TR, Kauff ND, Domchek SM. Meta-analysis of risk reduction estimates associated with risk-reducing salpingo-oophorectomy in BRCA1 or BRCA2 mutation carriers. J Natl Cancer Inst. 2009;101(2): 80-87

87. Kauff ND, Satagopan JM, Robson ME, et al. Risk-reducing salpingooophorectomy in women with a BRCA1 or BRCA2 mutation. $N$ Engl J Med. 2002;346(21):1609-1615.

88. Rebbeck TR, Lynch HT, Neuhausen SL, et al. Prophylactic oophorectomy in carriers of BRCA1 or BRCA2 mutations. $N$ Engl J Med. 2002;346(21):1616-1622.

89. Narod SA, Sun P, Ghadirian P, et al. Tubal ligation and risk of ovarian cancer in carriers of BRCA1 or BRCA2 mutations: a case-control study. Lancet. 2001;357(9267):1467-1470.

90. Kauff ND, Domchek SM, Friebel TM, et al. Risk-reducing salpingooophorectomy for the prevention of BRCA1- and BRCA2-associated breast and gynecologic cancer: a multicenter, prospective study. J Clin Oncol. 2008;26(8):1331-1337.

91. Eisen A, Lubinski J, Klijn J, et al. Breast cancer risk following bilateral oophorectomy in BRCA1 and BRCA2 mutation carriers: an international case-control study. J Clin Oncol. 2005;23(30):7491-7496.

92. Paley PJ, Swisher EM, Garcia RL, et al. Occult cancer of the fallopian tube in BRCA-1 germline mutation carriers at prophylactic oophorectomy: a case for recommending hysterectomy at surgical prophylaxis. Gynecol Oncol. 2001;80(2):176-180.

93. Aziz S, Kuperstein G, Rosen B, et al. A genetic epidemiological study of carcinoma of the fallopian tube. Gynecol Oncol. 2001;80(3): $341-345$.

94. Rebbeck TR, Friebel T, Wagner T, et al. Effect of short-term hormone replacement therapy on breast cancer risk reduction after bilateral prophylactic oophorectomy in BRCA1 and BRCA2 mutation carriers: the PROSE Study Group. J Clin Oncol. 2005;23(31):7804-7810.

95. Botkin JR, Smith KR, Croyle RT, et al. Genetic testing for a BRCA1 mutation: prophylactic surgery and screening behavior in women 2 years post testing. Am J Med Genet A. 2003;118A(3):201-209.

96. Kram V, Peretz T, Sagi M. Acceptance of preventive surgeries by Israeli women who had undergone BRCA testing. Fam Cancer. 2006;5(4):327-335.

97. Lerman C, Hughes C, Croyle RT, et al. Prophylactic surgery decisions and surveillance practices one year following BRCA1/2 testing. Prev Med. 2000;31(1):75-80.

98. Beattie MS, Crawford B, Lin F, Vittinghoff E, Ziegler J. Uptake, time course, and predictors of risk-reducing surgeries in BRCA carriers. Genet Test Mol Biomarkers. 2009;13(1):51-56.

99. Scheuer L, Kauff N, Robson M, et al. Outcome of preventive surgery and screening for breast and ovarian cancer in BRCA mutation carriers. J Clin Oncol. 2002;20(5):1260-1268.
The Application of Clinical Genetics

\section{Publish your work in this journal}

The Application of Clinical Genetics is an international, peer-reviewed open access journal that welcomes laboratory and clinical findings in the field of human genetics. Specific topics include: Population genetics; Functional genetics; Natural history of genetic disease; Management of genetic disease; Mechanisms of genetic disease; Counselling and

\section{Dovepress}

ethical issues; Animal models; Pharmacogenetics; Prenatal diagnosis; Dysmorphology. The manuscript management system is completely online and includes a very quick and fair peer-review system, which is all easy to use. Visit http://www.dovepress.com/testimonials.php to read real quotes from published authors. 